\title{
Dangers of fatigue
}

\author{
Fiona Godlee editor in chief
}

The BMJ

Health systems in the northern hemisphere are gearing up for winter. In the UK this brings traditional prognostications of doom, which were heightened last week by an unprecedented public call for more money from NHS England's chief executive (doi:10.1136/bmj.j5251). Our own veteran reporter of winter crises, Nigel Hawkes, wonders whether this time the NHS really will fall over, not from sudden collapse but from slow strangulation (doi:10.1136/bmj.j5203). With "winter" pressures now apparent all year round, the cause is not more patients arriving at hospitals, he says, but fewer patients leaving. Until 2013 lengths of stay were falling, but this trend has reversed in the past four years, with the finger being pointed at growing problems in social care.

"We face winter better prepared than we have ever been but more scared than we have ever been," says NHS England's chair, Malcolm Grant. Scared for patients, whose safety will be put at risk. Scared too, I would suggest, for doctors and others working in healthcare, who may themselves be put in harm's way because of fatigue and lack of support. As Paul Grieg and Rosamund Snow explain (doi:10.1136/bmj.j5107), needlestick injuries and road traffic crashes are more common when doctors are tired. And when mistakes are made, doctors suffer as well as their patients.
Other safety critical industries, such as air and road transport, now have clear rules to safeguard against fatigue. Staff can't opt out, and the rules take account of not only hours worked but the cumulative effect of patterns of work. Schedules and budgets have to take them into account. Not so in medicine. Grieg and Snow question the assumption that doctors' training makes them better able to overcome fatigue or to make their own judgments about risk. They find no evidence that doctors can evade the limitations of human physiology. At an individual level, they call on doctors to look for warning signs in themselves and their colleagues as part of their professional duty. "If you would not let a colleague work under the influence of alcohol, the same should apply to fatigue," they say.

At an organisational level, they make an equally strong plea for tighter oversight of working patterns at all levels of seniority, including how working hours are clustered, whether proper breaks are taken, and how much fatigue someone may be accumulating. Shorter shifts need not mean reduced safety if training includes how to do safe handovers. Some of us may be looking forward to a post-Brexit health service freed from the constraints of the European Working Time Directive. If we want to survive winter's pressures, perhaps we should think again. 